\title{
Report on the First Inter-American Conference on Astronomy at La Plata and Cordoba, October 30 to November 3, 1959
}

\author{
Prepared by Dirk Brouwer, Yale University Observatory, New Haven, Connecticut
}

The Conference was made possible through the generosity of the Argentine National Council for Scientific and Technical Research and the National University of La Plata, which together provided for all expenses for the participants while in Argentina. A grant from the United States National Science Foundation to the National Academy-National Research Council was made available to cover the travel expenses of most of the astronomers from outside Argentina.

The participants were:

Sr. C. Borel, Observatorio de La Plata, Argentina.

Dr. Dirk Brouwer, Director Yale University Observatory, New Haven, Connecticut, U. S. A.

Dr. C. U. Cesco, Director del Observatorio de San Juan, Argentina.

Dr. R. P. Cesco, Director del Observatorio de La Plata, Argentina.

Dr. G. M. Clemence, Scientific Director, U. S. Naval Observatory, Washington 25, D. C., U. S. A.

Mr. John S. Coleman, Executive Secretary, Division of Physical Sciences, U. S. National Academy of SciencesNational Research Council, Washington 25, D. C., U. S. A.

Dr. B. H. Dawson, Observatorio de La Plata, Argentina.

Sr. C. Etchecopar, Director del Observatorio Astronomico, Montevideo, Uruguay.

Dr. L. I. Gama, Director del Observatorio Astronomico de Rio de Janerio, Brazil.

Dr. L. Gratton, Director del Observatorio de Cordoba, Argentina.

Sr. M. Itzigsohn, Observatorio de La Plata, Argentina.

Dr. C. R. Jaschek, Observatorio de La Plata, Argentina.

Dr. J. Landi-Dessy, Observatorio de Cordoba, Argentina.

Sr. L. Milone, Observatorio de Cordoba, Argentina.

Dr. G. R. Miczaika, Geophysics Research Directorate, Air Force Cambridge Research Center, Bedford, Massachusetts, U. S. A.

Sr. C. Molina Serrano, Observatorio Astronomico de Quito, Ecuador.

Dr. W. W. Morgan, Yerkes Observatory, Williams Bay, Wisconsin, U. S. A.

Dr. G. F. W. Mulders, Astronomy Program, National Science Foundation, Washington 25, D. C., U. S. A.

Sr. J. J. Nissen, Observatorio de San Juan, Argentina.

Dr. F. Rutllant, Director del Observatorio Astronomico de la Universidad de Chile, Santiago de Chile, Chile.

Dr. J. Sahade, Observatorio de La Plata, Argentina.

Dr. Jan Schilt, Director Rutherfurd Observatory, Columbia University, New York 27, New York, U. S. A.

Mr. F. P. Scott, U. S. Naval Observatory, Washington 25, D. C., U. S. A.

Dr. S. Slaucitajs, Observatorio de La Plata, Argentina.

Mr. Malcolm Thompson, Dominion Observatory, Ottawa, Canada.

Additional members of the staffs of the La Plata and Cordoba Observatories, not listed as participants, attended some of the sessions.

The Conference was opened at 10:00 a.m. on Friday, October 30 at the La Plata Observatory with welcoming remarks by Dr. Danilo Vucetich, the president of the National University of La Plata, to which Dr. Clemence responded with greetings from the American Astronomical Society and the National Academy of Sciences.

Dr. Clemence opened the business session by saying that this conference was a continuation of the Cincinnati Conference of May, 1959. The resolutions of that meeting will be discussed and we hope now to make definite plans for an astrometric survey of the southern hemisphere involving work with meridian circles and Danjon astrolabes at several observatories. But our interest is deeper than astrometry only: it is desirable to have InterAmerican cooperation also in astrophysics and other branches of astronomy, and to exchange astronomers.

The Chairman, DR. R. P. CEsco, Director of the La Plata Observatory, noted with regret that the directors of the observatories in Mexico, Venezuela and Colombia, who had been invited to attend, were unable to be present.

A resolutions committee was appointed, composed of Brouwer (Chairman), Dawson, Gama, Gratton and Rutllant.

The chairman then asked each of the participants to describe the facilities and lines of research of his observatory, and report on special difficulties encountered, and on plans for the future. These informal reports served primarily as background information for later discussions on specific problems. 
A comment that occurred in several reports was that the interest in astronomical careers among younger people in Latin American institutions can be increased only if more attractive positions can be made available. In many cases younger staff members are forced to supplement their incomes by outside activities. In effect they then become only part-time astronomers.

At the next session in La Plata, on Saturday, October 31, copies of the Cincinnati Resolutions were distributed for discussion and comment. With regard to Resolution 2(c) ("That the Academy of Sciences of the U.S.S.R. proceed with its plan of organizing in the near future an expedition to the southern hemisphere to engage in an intensive program of astrometric observations"), the representatives of Argentinian and Chilian observatories reported that both nations had received letters from the U.S.S.R. Academy on this subject. It was noted that these letters were in accord with the language of this Cincinnati Resolution and that the question of replies to them was one to be dealt with by the governments of Argentina and Chile.

The Conference endorsed the Cincinnati Resolutions unanimously with the understanding that some of the resolutions resulting from the present meeting are to be considered as amendments to the Cincinnati Resolutions.

On Sunday, November 1, the members of the Conference traveled by chartered plane to Cordoba via Villa Dolores where a visit was made to the satellite tracking station operated by the Smithsonian Astrophysical Observatory.

On Monday, November 2, the Conference resumed at the Cordoba Observatory with DR. Gratton presiding. Five items had been placed on the agenda:

\section{Interchange of Astronomers and Instruments}

Mr. John Coleman stated that there are numerous agencies in the United States offering fellowship programs. His office in the National Research Council has access to information about these programs. He suggested that South American astronomers who wish to go to the United States write to him.

Mr. Malcolm Thompson reported on post-doctoral fellowships administered by the Canadian Research Council that are open to non-Canadians.

Latin American observatories are also interested in attracting experienced North American astronomers as visitors to use their instruments, to give seminars, and to teach. The budgets of some Latin American observatories provide for allowances for room and board and other living expenses, but generally not for travel. Mr. Coleman suggested that such exchanges be made on an individual basis by the Latin and North American institutions concerned whenever possible. The United States National Academy of Sciences is willing to assist in facilitating initial contacts and possibly in securing financial aid for the necessary travel.

A review of the exchanges of astronomers that had already taken place or were expected during the coming year showed considerable activity, but a number of specific needs remain to be satisfied.

\section{Publications from South American Observatories}

Dr. Gratton stated that South American research in astronomy is not as well known in other countries as it should be, partly because much of the work is published in observatory publications which have a low diffusion, partly because of the language difficulty. Publication in the United States journals is very limited because the U. S. page charges are high as a result of the unfavorable rate of exchange. It was remarked that the United States journals can occasionally waive page charges but that only limited funds are available for this purpose. Dr. Clemence offered to propose to the American Astronomical Society the granting of financial aid to publication of South American papers in United States journals and that in the meantime papers should not be withheld because of inability to pay page charges.

Dr. Schilt suggested that the Latin American countries consider establishing jointly a journal like the Bulletin of the Astronomical Institutes of the Netherlands. This publication stimulated astronomy in the Netherlands and demonstrated to astronomers all over the world the high level of astronomical activity in that country.

Dr. Sahade remarked that it would be necessary to wait a few years before such a solution could be realized. The consensus among the Latin American astronomers present appeared to be that there are not yet enough contributions to create a successful journal.

\section{Permanent Inter-American Committee}

Dr. Gratton suggested that a group of four or five astronomers be formed to consider and coordinate problems of cooperation between North and South American astronomers: for example, the planning of future conferences. Mr. Coleman said that recently a subcommittee of the United States National Committee of the International Astronomical Union had been formed to consider Inter-American cooperation in Astronomy, and he proposed that two of its members also be members of the new permanent committee under discussion. He also remarked that the 